\title{
Addressing our planetary crisis
}

\section{Consensus statement from the presenters and International Advisory Committee of the Regional Action on Climate Change (RACC) Symposium held in conjunction with the Kyoto- based Science and Technology in Society (STS) Forum, 1 October 2021}

\author{
Jim Falk ${ }^{1,2} \cdot$ Faten Attig-Bahar $^{3} \cdot$ Rita R. Colwell $^{4,5} \cdot$ Swadhin K. Behera $^{6,7} \cdot$ Adel S. El-Beltagy $^{8} \cdot$ Joachim von Braun $^{9,10}$. \\ Partha Dasgupta ${ }^{11}$. Peter H. Gleick ${ }^{12}$. Ryuichi Kaneko ${ }^{13}$. Charles F. Kennel ${ }^{14,15}$. Phoebe Koundouri ${ }^{16}$. \\ Yuan Tseh Lee ${ }^{17} \cdot$ Thomas E. Lovejoy $^{18,19} \cdot$ Amy Luers $^{20} \cdot$ Cherry A. Murray $^{21,22} \cdot$ Rattan Lal $^{23} \cdot$ Ismail Serageldin $^{24}$. \\ Youba Sokona ${ }^{25} \cdot$ Kazuhiko Takeuchi $^{26,27} \cdot$ Makoto Taniguchi ${ }^{28} \cdot$ Chiho Watanabe $^{29,30} \cdot$ Tetsuzo Yasunari $^{28,31}$
}

Published online: 1 November 2021

(c) The Author(s), under exclusive licence to Springer Japan KK, part of Springer Nature 2021

Keywords Climate change $\cdot$ Biodiversity $\cdot$ Population growth $\cdot$ Risk interaction

The Earth's climatic, ecological, and human systems are converging towards an existential crisis for global civilization within the lifetimes of children now living. Precursors of that crisis are already evident and likely to be further amplified as human population peaks around the end of the twenty-first century. A year ago, the statement from the Regional Action on Climate Change (RACC) Symposium declared " 2020 is the year when humanity is experiencing ...converging impacts of climate change, biodiversity loss, pollution, inadequate global health infrastructures, and stark inequalities" (Falk et al. 2020).

That reality is even more evident now. Current policies are projected to produce a rise of $3 \mathrm{deg}$ or more above pre-industrial levels in less than 80 years. Accompanying impacts are described in compelling detail in the recent Intergovernmental Panel on Climate Change, Working Group 1 Report (Masson-Delmotte et al. 2021).

Taken together this represents a serious trend in declining planetary health. The existing implosion of biodiversity is accelerating, and significant new threats to food security and public health are emerging, stressed further by population growth, inequitable distribution and consumption of resources, and significant demographic shifts. Notably, but

More details of the RACC and its International Advisory Committee are set out at https://www.stsforum.org/racc/iac.php.

Jim Falk

jfalk@unimelb.edu.au far from exclusively, through drought and unsustainable overdraft of groundwater in arid and semi-arid regions, the agricultural and food production on which billions of people are directly dependent is increasingly threatened. Many of these populations are already chronically malnourished and could face famine due to extreme poverty, displacement, climate change, and local conflicts. At the same time attempts to increase agricultural productivity using current approaches will further degrade biodiversity and increase emissions leading to further global warming.

Old notions of national military and economic security are no longer adequate. The pandemic of 2020-2021 (SARS-CoV-2) has shown how local disease outbreaks create global risks, and distant outbreaks create local impacts. Other converging risks (for example to climate and biodiversity) are showing similar dynamics. As a result, standalone risk management strategies will become increasingly ineffective. Recent experience suggests that nations need now to work towards a much more comprehensive human security and sustainability action program addressing a complex system of multiple risks simultaneously. To avoid converging catastrophes, we must confront multiple challenges with cross-disciplinary tools, transforming our societies in multiple ways and on multiple scales: locally, regionally and globally.

At its foundation in 2009 RACC-1 proposed the creation of specialized Knowledge-Action Networks (KANs) intended to support adaptation to local and regional impacts of climate change. They were to be regionally specialized networks comprising international research specialists and 
regional and local decision-makers. KANs were intended to supply crucial relevant and trustworthy scientific knowledge applicable to decision makers at local and regional scale and to enhance their adaptive and coping capacity. This should lead to building resilience in the most vulnerable eco-regions (El-Beltagy 2019).

This year, following RACC-13, the starting point for effective action is still decisions based on trustworthy knowledge. But multiple risk convergence requires more of 'knowledge action' (networks of people and institutions to provide knowledge interacting with networks of people and institutions who influence, create, and implement policy). These networks need now to be more widely distributed geographically and capable of integrating more complex scientific knowledge and transmitting successful approaches in one region to others.

We believe a global initiative is required urgently to coordinate and increase the collaboration of existing relevant information hubs. This should be facilitated by appropriate human support and information technology and tasked with supporting multi-risk situational awareness for regional and local decision makers.

In anticipation of the need to support a broad security and sustainability action agenda, international agencies like the World Meteorological Organization (WMO), World Health Organisation (WHO), Food and Agriculture Organization (FAO), UN Water, Intergovernmental Oceanographic Commission (IOC) and others should be encouraged to further integrate their knowledge resources. The capability of the WMO's Global Earth Observation System of Systems (GEOSS) to support a comprehensive security and sustainability agenda should be developed. The pooling and integration of relevant data can begin in tandem with the development of more appropriate standardized and timely reporting and information systems and institutional, regulatory and governance structures.

RACC's role has been to urge that relevant policies and actions be thought through at both the global and regional levels together. Over more than a decade since RACC-1 relevant thinking has become more integrated. Mitigation and adaptation are now seen as complementary parts of the climate action agenda, biodiversity is being integrated into economic planning, and there is increasing interest in research in geo-engineering, whose acceptability depends on the progress (or lack thereof) in the other components of the security and sustainability agenda.

Key actions of this agenda in climate and biodiversity include accelerating, articulating and applying simultaneously at local, regional, national and global scales decisions to:

Mitigate climate change: decarbonize the world economy in the next 3 decades (reducing net emitted greenhouse gases to zero) and increase carbon drawdown (including by re-carbonization of world soils and vegetation).

Conserve and restore biodiversity: adopt a goal of no net global loss of ecosystem services by 2035 . This needs to be supported by increased broad protection for natural ecosystems and biodiversity through expansion of land, water, and ocean reserves and protection, restoration of damaged ecosystems and soils, regenerative agriculture, gene banks and policies protecting threatened and endangered species.

Internalise into pricing the value of natural services: in support of the above develop the necessary international institutions, accounting systems, financing, processes and agreements to reflect back into pricing the value of currently unpriced natural services to support widespread investment into circular economies and nature-based solutions to ecological degradation (as developed in Dasgupta 2021).

Build resilience and reduce societal exposure to those impacts which cannot be avoided: do this through clearly planned investment in infrastructure, nature-based solutions and capacity development that facilitate adaptation, disaster risk management, and support for and sustainable development of the most vulnerable. Prepare for and provide global support for investment in the protection, retreat, or relocation of vulnerable populations especially vulnerable to depleting resources and climate extremes.

Identify effective protective and restorative options: accelerate research and analysis, but not currently deployment, of measures that might effectively reduce the speed and severity of soil degradation, biodiversity loss and climate change, including proposed methods for restoring biospheric processes, carbon drawdown, and regionally applicable albedo modification. Such investigations should be subject to best-available scientific analysis of potential risks and benefits. As do the US National Academies of Science (2021), we consider that careful governance (with representation of all stakeholders and incorporating ethics and justice considerations for future generations) needs to be developed, and will be critical for determining what research, in what manner, and under what controls, such research may proceed.

\section{References}

Dasgupta P (2021) The economics of biodiversity: the Dasgupta review. Full report. HM Treasury, London. https://www.gov.uk/ government/publications/final-report-the-economics-of-biodiversi ty-the-dasgupta-review. Accessed 28 Oct 2021

El-Beltagy A (2019) Navigating through uncertainties: agro-ecosystems affected by dynamic impact of climate change. In: Proceedings of the 13th ICDD Conference, Jodhpur, India, 11-14 February, 2019. ISBN: 978-81-901024-3-8

Falk J, Colwell R, El-Beltagy A, Gleick P, Kennel C, Lee YT, Luers A, Murray C, Serageldin I, Takeuchi K, Watanabe C, Yasunari 
T (2020) Beyond 2020: converging crises demand integrated responses Statement by the RACC International Advisory Committee following the RACC-12. Int Forum Sustain Sci 16(2):691693. https://doi.org/10.1007/s11625-020-00876-w

Masson-Delmotte V, Zhai P, Pirani A, Connors SL, Péan C, Berger S, Caud N, Chen Y, Goldfarb L, Gomis MI, Huang M, Leitzell K, Lonnoy E, Matthews JBR, Maycock TK, Waterfield T, Yelekçi O, Yu R, Zhou B, IPCC (2021) Climate change 2021: the physical science basis contribution of working group I to the sixth assessment report of the intergovernmental panel on climate change. Cambridge University Press, Cambridge
National Academies of Science (2021) Engineering-medicine, reflecting sunlight: recommendations for solar geoengineering research and research governance 2021, US. https://www.nap.edu/catalog/ 25762/reflecting-sunlight-recommendations-for-solar-geoenginee ring-research-and-research-governance. Accessed 28 Oct 2021

Publisher's Note Springer Nature remains neutral with regard to jurisdictional claims in published maps and institutional affiliations.

\section{Authors and Affiliations}

$\mathrm{Jim}_{\text {Falk }}{ }^{1,2} \cdot$ Faten Attig-Bahar $^{3} \cdot$ Rita R. Colwell $^{4,5} \cdot$ Swadhin K. Behera ${ }^{6,7} \cdot$ Adel S. El-Beltagy $^{8} \cdot$ Joachim von Braun $^{9,10}$. Partha Dasgupta ${ }^{11}$. Peter H. Gleick ${ }^{12}$. Ryuichi Kaneko ${ }^{13}$. Charles F. Kennel ${ }^{14,15}$. Phoebe Koundouri ${ }^{16}$. Yuan Tseh Lee ${ }^{17}$. Thomas E. Lovejoy ${ }^{18,19} \cdot$ Amy Luers $^{20}$. Cherry A. Murray ${ }^{21,22} \cdot$ Rattan Lal $^{23} \cdot$ Ismail Serageldin ${ }^{24}$. Youba Sokona ${ }^{25} \cdot$ Kazuhiko Takeuchi $^{26,27}$. Makoto Taniguchi ${ }^{28} \cdot$ Chiho Watanabe $^{29,30} \cdot$ Tetsuzo Yasunari $^{28,31}$

1 Melbourne Sustainable Society Institute, University of Melbourne, Melbourne, Australia

2 University of Wollongong, Wollongong, Australia

3 Tunisia Polytechnic School, University of Carthage, Tunis, Tunisia

4 Center for Bioinformatics and Computational Biology, University of Maryland, College Park, USA

5 Johns Hopkins Bloomberg School of Public Health, Baltimore, USA

6 Application Laboratory, Japan Agency for Marine-Earth Science and Technology (JAMSTEC), Yokosuka, Japan

7 Department of Ocean Technology, Policy, and Environment, The University of Tokyo, Tokyo, Japan

8 International Dryland Development Commission, Arid Land Agricultural Graduate Studies and Research Institute, Ain Shams University, Cairo, Egypt

9 Pontifical Academy of Sciences, Vatican City, Vatican City

10 Center for Development Research (ZEF), Bonn University, Bonn, Germany

11 Faculty of Economics, University of Cambridge, Cambridge, UK

12 Pacific Institute for Studies in Development, Environment and Security, Oakland, USA

13 School of Political Science and Economics, Meiji University, Tokyo, Japan

14 Scripps Institution of Oceanography, University of California (UCSD), San Diego, USA

15 Centre for Science and Policy, University of Cambridge, Cambridge, UK
16 ReSEES Research Laboratory, Sustainable Development Unit and EIT Climate-KIC Hub, Athena Research Center, Athens University of Economics and Business, Athens, Greece

17 Academia Sinica, Taipei, Taiwan

18 Department of Environmental Science and Policy, George Mason University, Fairfax, USA

19 United Nations Foundation, Washington, DC, USA

20 Sustainability Science, Microsoft, Redmond, USA

21 Harvard University, Cambridge, USA

22 University of Arizona, Tucson, USA

23 CFAES Rattan Lal Center for Carbon Management and Sequestration, The Ohio State University, Columbus, USA

24 The Library of Alexandria, Alexandria, Egypt

25 University College London (UCL), London, UK

26 Institute for Global Environmental Strategies (IGES), Kanagawa, Japan

27 Institute for Future Initiatives (IFI), The University of Tokyo, Tokyo, Japan

28 RIHN Center, Research Institute for Humanity and Nature (RIHN), Kyoto, Japan

29 School of Tropical Medicine and Global Health, Nagasaki University, Nagasaki, Japan

30 The University of Tokyo, Tokyo, Japan

31 Kyoto Climate Change Adaptation Center (KCCAC), Kyoto, Japan 